\title{
Association of Gender with Class II Cast Metal or Ceramic Restoration in MO and DO of Mandibular Molars- A Retrospective Study
}

\author{
Karthik EVG ${ }^{1}$, Manish Ranjan* and Uma Maheshwari T.N ${ }^{2}$ \\ ${ }^{1}$ Saveetha Dental College and Hospitals, Saveetha Institute of Medical and Technical Sciences, \\ Saveetha University, Chennai-77. \\ *Department of Conservative Dentistry \& Endodontics, Saveetha Dental College and Hospitals, \\ Saveetha Institute of Medical and Technical Sciences, Saveetha University, Chennai-77. \\ Department of Oral Medicine. Saveetha Dental College and Hospitals, Saveetha Institute of \\ Medical and Technical Sciences, Saveetha University, Chennai-77, India \\ Corresponding author email: manish@saveetha.com
}

\begin{abstract}
Dental caries being the major reason for predominant loss of tooth structure, several other reasons such as erosion, attrition, abfraction and fracture are also major reasons for the loss of hard tissue and eventually necessitating the requirement for a direct or an indirect restoration. Caries involving the proximal aspect of the truth in the posterior teeth are categorised as Class II caries and the restoration of it can be called as a class II restoration. Composite Restorations have also found a variety of applications in the modern dentistry. The primary advantage of composite is they are time and cost efficient with a very good aesthetic value. The aim of the study is to check the prevalence of a class II cast metal or ceramic restoration in mandibular molars. The current study is an institutional based retrospective study performed over a review of 49832 cases. Chi-square tests were performed between the obtained parameters. The results obtained show the prevalence of class II cast metal or ceramic restoration in lower molars. Within the limitations of the study, the most common type of restoration is Class 2 ceramic inlay in the disto-occlusal aspect. The most common gender is male and the most common affected tooth is 46 .
\end{abstract}

\section{KEY WORDS: CLASS II PROXIMAL RESTORATION; CAST METAL; CERAMIC; MANDIBULAR MOLARS.}

\section{INTRODUCTION}

Dental caries being the major reason for predominant loss of tooth structure, several other reasons such as erosion, attrition, abfraction, fracture are also a major reason for the loss of hard tissue and eventually necessitating the requirement for a direct or an indirect restoration. There are two types of restorations that were commonly used to restore teeth namely, direct or indirect restoration. Caries involving the proximal aspect of the truth in the posterior teeth are categorised as Class II caries and the restoration

Biosc Biotech Res Comm P-ISSN: 0974-6455 E-ISSN: 2321-4007

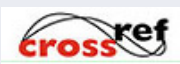

Identifiers and Pagination

Year: 2021 Vol: 14 No (10) Special Issue

Pages: $18-23$

This is an open access article under Creative

Commons License Attribn 4.0 Intl (CC-BY).

DOI: $h t t p: / / d x . d o i . o r g / 10.21786 / b b r c / 14.10 .4$ of it can be called as a class II restoration. There are three types of class II restoration, which are Class II MO (MesioOcclusal), Class II DO (Disto-occlusal) and Class II MOD (Mesio-disto-occlusal) aspects. Direct restorations i.e., composites are used in areas where there is minimal loss of tooth structure. Indirect restorations such as cast metal, gold or ceramic restorations are widely used when the loss of tooth structure is more than 50\% (Nandini, 2010; Chu et al., 2013; Azeem and Sureshbabu, 2018; Rashid et al., 2015; Azeem and Sureshbabu, 2018; Choudhari and Ranjan, 2019; Gopalasamy and Ranjan, 2020).

Cast Gold metal restorations were very popular in the past due to their excellent resistance to corrosion, minimal preparation and ease of handling and finishing, durability and longevity. The introduction of metal ceramic and all ceramic restorations in the late 1950s have had an impact on the treatment plan due to the survival rate of $94.7 \%$. All ceramic restorations became very popular due to the high strength and aesthetics. The primary principal advantage of ceramic

\section{Article Information}

Received: $08^{\text {th }}$ Aug 2021

Accepted after revision: $19^{\text {th }}$ Oct 2021 
restorations is their low fracture rate and high flexural strength (Shenoy and Shenoy, 2010; Givan, 2014; Givan, 2014; Zhang and Kelly, 2017; Azeem and Sureshbabu, 2018; Ravinthar and Jayalakshmi, 2018; Gopalasamy and Ranjan, 2020).

Composite Restorations have also found a variety of applications in the modern dentistry. The primary advantage of composite is they are time and cost efficient with a very good aesthetic value. The main disadvantages of composites are, polymerisation shrinkage and high occlusal wear. The seal and longevity of a composite restoration depends on various factors such as dimensions, shape, location, $\mathrm{C}$ factor, type of tooth and its load distribution (Nasim et al., 2010; Cramer et al., 2011; Malta etal., 2014; Soares et al., 2017; Soares et al., 2017; Azeem and Sureshbabu, 2018; Ravinthar and Jayalakshmi, 2018; Gopalasamy and Ranjan, 2020).

Indirect restorations have an upper hand in strength when compared to composites. Indirect restorations are exposed to light, heat and pressure in the lab which has significant strength and significant increase in the monomer polymer conversion rate and thus high young modulus and highly flexural strength are obtained. Previously our team has a rich experience in working on various research projects across multiple disciplines (Malta et al., 2014; Cramer et al., 2011; Gargari et al., 2013; Soares et al., 2017; Gheena and Ezhilarasan, 2019; Ke et al., 2019; Malli Sureshbabu et al., 2019; Mehta et al., 2019; Samuel et al., 2019; Sharma et al., 2019; Varghese et al., 2019; Venu et al., 2019; Vignesh et al., 2019; Jain et al., 2019; Jose et al., 2020; Krishnaswamy et al., 2020; Muthukrishnan et al., 2020; Samuel et al., 2020; Sathish and Karthick, 2020). Now the growing trend in this area motivated us to pursue this project. Despite the extensive literature present, there is no consensus on which restoration is more beneficial. The aim of this study is to check the frequency of the type of cast metal restoration used in the lower molars and the incidence of cast metal restoration in mandibular molars.

\section{MATERIAL AND METHODS}

The current study was an institutional based retrospective study performed at Saveetha dental college. All the data collected was cross verified by an examiner to avoid any missing case records. All the incomplete case records were eliminated. A total of 31 subjects who underwent a class II cast metal or ceramic restoration in mandibular molars were chosen for the study in a total of 49,832 subjects screened for the data. The data was evaluated between all the composite class II restored teeth along with class II ceramic or cast metal restored teeth. All the data collected was formatted and tabulated using Microsoft Excel (Version - 2020). All the care records and treatment records were obtained from the patient management software. The dependent variable was attrition and lower molars. The statistical analysis was performed using IBM SPSS (Version - 24). Our institution is passionate about high quality evidence based research and has excelled in various fields (Pc et al., 2018; Ramesh et al., 2018; Ezhilarasan et al., 2019; Ramadurai et al., 2019; Sridharan et al., 2019; Vijayashree, 2019; Mathew et al., 2020). We hope this study adds to this rich legacy.

\section{RESULTS AND DISCUSSION}

In this study we checked the frequency of the type of cast metal restoration used in the lower molars and the incidence of cast metal restoration in mandibular molars. Following results were obtained which were represented with different graphs.

\section{Figure 1: Age And Frequency Of Restoration}

Figure 1: shows the age to frequency of the restoration. $X$ axis denotes the age and the $\mathrm{Y}$ axis denotes the frequency of restoration. 25 - 30 years of age subjects showed the highest frequency of undergoing ceramic restoration while 40 - 60 showed metal restoration. Mean obtained was 35 and the standard deviation was $\mathbf{1 0 . 8}$.

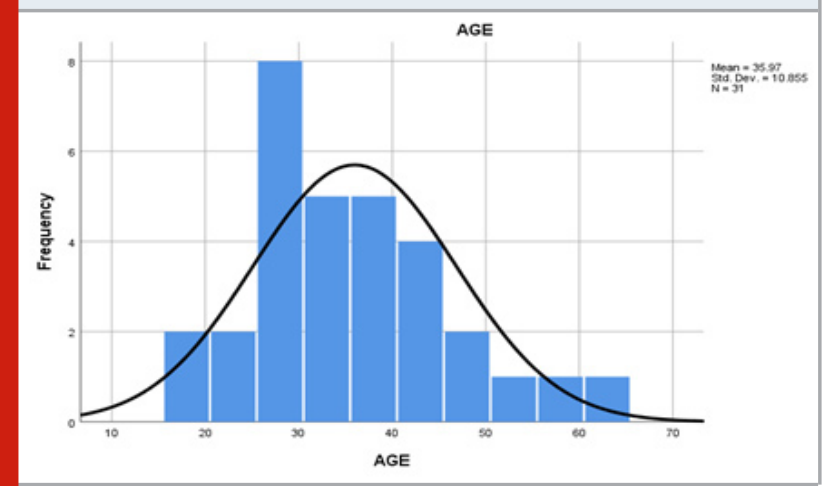

Figure 2: Sex And Frequency Of Restoration

Figure 2: Shows the frequency of restoration in specific gender groups. 1 on the graph legend denotes male and 2 on the graph legend denotes female. $X$ axis denotes the gender groups and the $\mathrm{Y}$ axis denotes the frequency of restorations

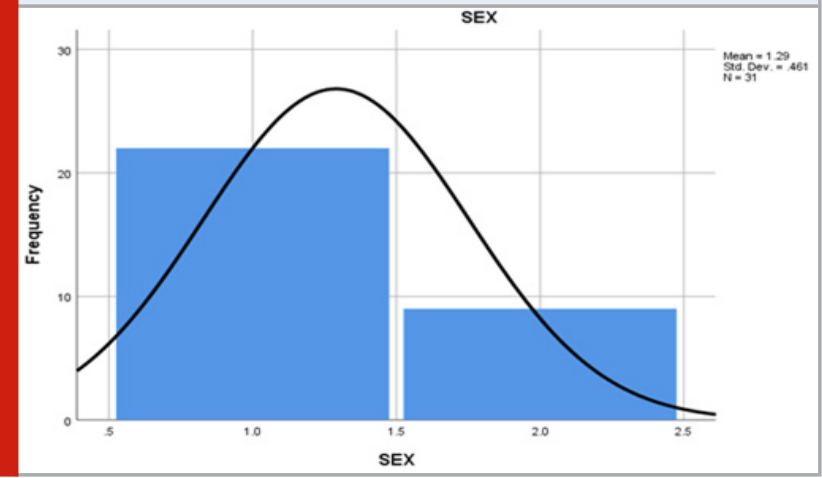

Figure 3: Type Of Restoration Vs Tooth Number

\section{Figure 4: Sex Vs Type Of Restoration}

With the above obtained results, ceramic MO followed by ceramic DO follow by metal DO were the frequencies of restorations observed. Also, 46 has the highest incidence of 12 , followed by 36 of 9 and 37, 47 with 5 each. A study conducted by Djiken et al., Showed that 19 out of 29 
showed significant success rate of ceramic restorations. A study conducted by Suleiman et.al inlays/onlays showed a $97.4 \%$ success rate i.e., 1082/1093 subjects when compared to direct restorations. However, in the current knowledge of the author, there is no previous study which shows the prevalence/frequencies of the types of Class 2 restorations. (Bona et al., 2008; Morimoto et al., 2016; Rajendran et al., 2019; Jose et al., 2020).

Figure 3: shows the association between the different teeth and the different types of restoration. The $x$-axis denotes the tooth and $y$-axis represents the number of different types of restorations. Three types of restorations were included in this study. In this graph blue colour shows Class II metal inlay DO, Red colour shows Class 2 ceramic inlay MO, Green colour shows Class 2 ceramic inlay DO and orange colour shows the total no. of cast restoration in that tooth. The Pearson chi-square value obtained was 6.763. The $p$ value obtained was 0.343 (p. $>0.05$ ) which shows the association between the tooth number and the type of restoration as non-significant, even though Class 2 metal inlay DO have its highest incidence in $\mathbf{3 6}$, ceramic inlay in 37,46 and ceramic inlay MO in 46 respectively. A total of 14 Class 2 ceramic MO and 13 ceramics DO were observed.

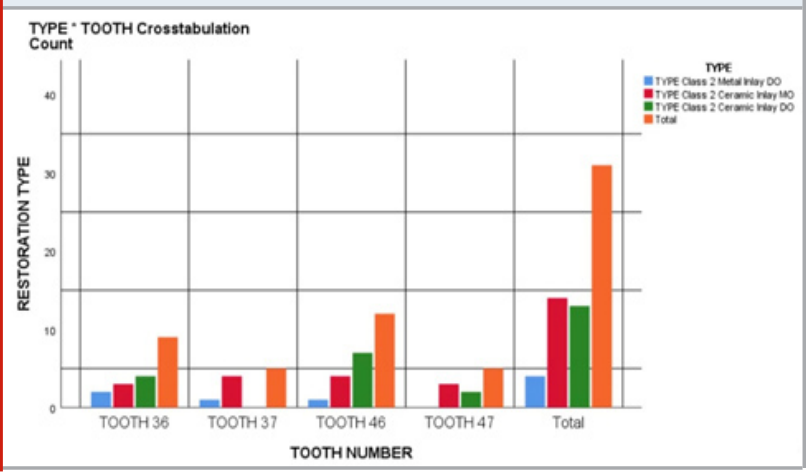

Previously our team had conducted numerous clinical trials (Ramamoorthi et al., 2015a; Nasim et al., 2018; Janani et al., 2020), in vitro studies (Ramanathan and Solete, 2015; Nandakumar and Nasim, 2018; Teja et al., 2018; Rajendran et al., 2019; Siddique et al., 2019) and surveyed (Manohar and Sharma, 2018; Jose et al., 2020) and reviewed various aspects of endodontics and conservative dentistry (Noor et al., 2016; Kumar et al., 2018; Ravinthar and Jayalakshmi, 2018; Rajakeerthi and Ms, 2019; Teja and Ramesh, 2019; Ravinthar and Jayalakshmi, 2018; Rajakeerthi and Ms, 2019) over the past five years (Ramamoorthi et al., 2015b; Ramanathan and Solete, 2015; Noor et al., 2016; Neelakantan et al., 2017; Manohar and Sharma, 2018; Nasim and Nandakumar, 2018; Rajakeerthi and Ms, 2019; Ramanathan and Solete, 2015; Noor et al., 2016; Kumar et al., 2018; Janani et al., 2020).Now we are focusing on retrospective studies, the idea for which has stemmed from the current interest in our community. Relatively small sample size and specific group population were the limitations of the study and not being able to assess the etiology of attrition. A larger sample size, proper diagnosis, treatment planning and to analyse the various restorative options can add significance to the study.
Figure 4: shows the association between gender and the no of different types of restoration. The $x$-axis denotes restorations in gender and $y$-axis represents the no. of restorations. Three types of restorations were included in this study.In this graph , blue colour represents male, red colour represents female and green colour represents total number. The statistics show that males have higher incidence than females. A total of 22 males and 9 female subjects were observed in the study. There is no significant association between gender and type of restoration as the p value obtained was $.974(>0.05)$ making the correlation non-significant, but the obtained values show that for any kind of restorations males were more in numbers. A total of 4 class II metal DO, followed by 8 Class II ceramic DO and 10 ceramic class II ceramic MO was observed in males, while 1 class II metal DO, 4 ceramic class II ceramic MO and 4 ceramic class II DO was observed in female subjects.

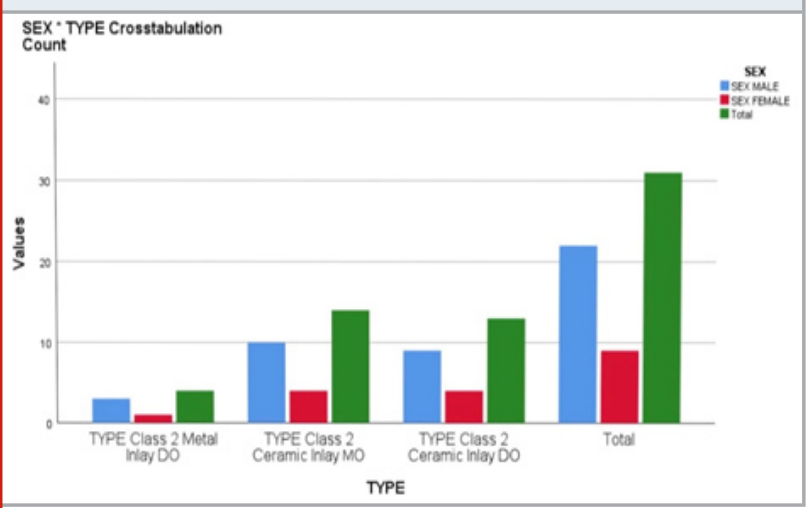

\section{CONCLUSION}

Within the limitations of the study, the most common type of restoration is Class 2 ceramic inlay in the disto-occlusal aspect. The most common effective gender is male and the most common affected tooth is 46 .

\section{REFERENCES}

Azeem, R. A. and Sureshbabu, N. M. (2018). Clinical performance of direct versus indirect composite restorations in posterior teeth: A systematic review. Journal of conservative dentistry: JCD, 21(1), pp. 2-9.

Bona, A. D., Della Bona, A. and Robert Kelly, J. (2008). The Clinical Success Of All-Ceramic Restorations. The Journal of the American Dental Association, pp. S8-S13. doi: 10.14219/jada.archive.2008.0361.

Choudhari, S. and Ranjan, M. (2019). Knowledge, awareness, and perception regarding occlusal stamp technique for composite restorations. Drug Invention Today, 11(10), pp. 2512-2517.

Chu, C.-H. et al. (2013). Restoring proximal caries lesions conservatively with tunnel restorations. Clinical, cosmetic and investigational dentistry, 5, pp. 43-50.

Cramer, N. B., Stansbury, J. W. and Bowman, C. N. (2011). Recent advances and developments in composite dental 
restorative materials. Journal of dental research, 90(4), pp. 402-416.

Ezhilarasan, D., Apoorva, V. S. and Ashok Vardhan, N. (2019). Syzygium cumini extract induced reactive oxygen species-mediated apoptosis in human oral squamous carcinoma cells. Journal of oral pathology \& medicine: official publication of the International Association of Oral Pathologists and the American Academy of Oral Pathology, 48(2), pp. 115-121.

Gargari, M. et al. (2013). Restoration of anterior teeth using an indirect composite technique. Case report. Oral \& implantology, 6(4), pp. 99-102.

Gheena, S. and Ezhilarasan, D. (2019). Syringic acid triggers reactive oxygen species-mediated cytotoxicity in HepG2 cells. Human \& experimental toxicology, 38(6), pp. 694-702.

Givan, D. A. (2014). Precious metal alloys for dental applications. Precious Metals for Biomedical Applications, pp. 109-129. doi: 10.1533/9780857099051.2.109.

Gopalasamy, K. and Ranjan, M. (2020). Knowledge, Awareness and Perception of Cention Being Used as A Replacement for Amalgam Restoration. International Journal of Research in Pharmaceutical Sciences, pp. 7-12. doi: 10.26452/ijrps. v11i1.1777.

Janani, K., Palanivelu, A. and Sandhya, R. (2020). Diagnostic accuracy of dental pulse oximeter with customized sensor holder, thermal test and electric pulp test for the evaluation of pulp vitality - An in vivo study. Brazilian Dental Science. doi: 10.14295/bds.2020. v23i1.1805.

Jose, J., Ajitha and Subbaiyan, H. (2020). Different treatment modalities followed by dental practitioners for Ellis class 2 fracture - A questionnaire-based survey. The open dentistry journal, 14(1), pp. 59-65.

Jose, J., P., A. and Subbaiyan, H. (2020). Different Treatment Modalities followed by Dental Practitioners for Ellis Class 2 Fracture - A Questionnaire-based Survey. The Open Dentistry Journal, pp. 59-65. doi: 10.2174/1874210602014010059.

Ke, Y. et al. (2019). Photosynthesized gold nanoparticles from Catharanthus roseus induces caspase-mediated apoptosis in cervical cancer cells (HeLa). Artificial cells, nanomedicine, and biotechnology, 47(1), pp. 19381946.

Krishnaswamy, H. et al. (2020). Investigation of air conditioning temperature variation by modifying the structure of passenger car using computational fluid dynamics. Thermal science, 24(1), pp. 495-498.

Kumar, D. and Delphine Priscilla Antony, S. (2018). Calcified Canal and Negotiation-A Review. Research Journal of Pharmacy and Technology, p. 3727. doi: 10.5958/0974-360x.2018.00683.2.

Malli Sureshbabu, N. et al. (2019). Concentrated Growth
Factors as an Ingenious Biomaterial in Regeneration of Bony Defects after Periapical Surgery: A Report of Two Cases. Case reports in dentistry, 2019, p. 7046203.

Malta, D. A. M. P., Magne, P. and Monteiro-Junior, S. (2014). Bond strength and monomer conversion of indirect composite resin restorations, Part 1: Light vs heat polymerization. The journal of adhesive dentistry, 16(6), pp. 517-522.

Manohar, M. and Sharma, S. (2018). A survey of the knowledge, attitude, and awareness about the principal choice of intracanal medicaments among the general dental practitioners and nonendodontic specialists. Indian Journal of Dental Research, p. 716. doi: 10.4103/ijdr. ijdr_716_16.

Manohar, M. P. and Sharma, S. (2018). A survey of the knowledge, attitude, and awareness about the principal choice of intracanal medicaments among the general dental practitioners and nonendodontic specialists. Indian journal of dental research: official publication of Indian Society for Dental Research, 29(6), pp. 716-720.

Mathew, M. G. et al. (2020). Evaluation of adhesion of Streptococcus mutans, plaque accumulation on zirconia and stainless steel crowns, and surrounding gingival inflammation in primary. Clinical oral investigations. Available at: https://link.springer.com/article/10.1007/ s00784-020-03204-9.

Mehta, M. et al. (2019). Oligonucleotide therapy: An emerging focus area for drug delivery in chronic inflammatory respiratory diseases. Chemico-biological interactions, 308, pp. 206-215.

Morimoto, S. et al. (2016). Survival Rate of Resin and Ceramic Inlays, Onlays, and Overlays: A Systematic Review and Meta-analysis. Journal of dental research, 95(9), pp. 985-994.

Muthukrishnan, S. et al. (2020). Support vector machine for modelling and simulation of heat exchangers. Thermal science, 24(1 Part B), pp. 499-503.

Nandakumar, M. and Nasim, I. (2018). Comparative evaluation of grape seed and cranberry extracts in preventing enamel erosion: An optical emission spectrometric analysis. Journal of conservative dentistry: JCD, 21(5), pp. 516-520.

Nandini, S. (2010). Indirect resin composites. Journal of Conservative Dentistry, p. 184. doi: 10.4103/09720707.73377.

Nasim, I. and Nandakumar, M. (2018). Comparative evaluation of grape seed and cranberry extracts in preventing enamel erosion: An optical emission spectrometric analysis. Journal of Conservative Dentistry, p. 516. doi: 10.4103/jcd.jcd_110_18.

Nasim, I. et al. (2010). Color stability of microfilled, microhybrid and nanocomposite resins-An in vitro study. Journal of Dentistry, pp. e137-e142. doi: 10.1016/j. 
jdent.2010.05.020.

Nasim, I. et al. (2018). Clinical performance of resinmodified glass ionomer cement, flowable composite, and polyacid-modified resin composite in noncarious cervical lesions: One-year follow-up. Journal of Conservative Dentistry, p. 510. doi: 10.4103/jcd.jcd_51_18.

Neelakantan, P. et al. (2017). Biofilms in EndodonticsCurrent Status and Future Directions. International Journal of Molecular Sciences, p. 1748. doi: 10.3390/ ijms18081748.

Noor, S. S. S. E., S Syed Shihaab and Pradeep (2016). Chlorhexidine: Its properties and effects. Research Journal of Pharmacy and Technology, p. 1755. doi: 10.5958/0974360x.2016. 00353.x.

Pc, J., Marimuthu, T. and Devadoss, P. (2018). Prevalence and measurement of anterior loop of the mandibular canal using CBCT: A cross sectional study. Clinical implant dentistry and related research. Available at: https:// europepmc.org/article/med/29624863.

R, R., Rajakeerthi, R. and Ms, N. (2019). Natural Product as the Storage medium for an avulsed tooth - A Systematic Review. Cumhuriyet Dental Journal, pp. 249-256. doi: 10.7126/cumudj.525182.

Rajendran, R. et al. (2019). Comparative Evaluation of Remineralizing Potential of a Paste Containing Bioactive Glass and a Topical Cream Containing Casein Phosphopeptide-Amorphous Calcium Phosphate: An in Vitro Study. Pesquisa Brasileira em Odontopediatria e Clínica Integrada, pp. 1-10. doi: 10.4034/ pboci.2019.191.61.

Ramadurai, N. et al. (2019). Effectiveness of 2\% Articaine as an anesthetic agent in children: randomized controlled trial. Clinical oral investigations, 23(9), pp. 3543-3550. Ramamoorthi, S., Nivedhitha, M. S. and Divyanand, M. J. (2015a). Comparative evaluation of postoperative pain after using endodontic needle and Endo Activator during root canal irrigation: A randomised controlled trial. Australian endodontic journal: the journal of the Australian Society of Endodontology Inc, 41(2), pp. 78-87.

Ramamoorthi, S., Nivedhitha, M. S. and Divyanand, M. J. (2015b). Comparative evaluation of postoperative pain after using endodontic needle and EndoActivator during root canal irrigation: A randomised controlled trial. Australian Endodontic Journal, pp. 78-87. doi: 10.1111/ aej.12076.

Ramanathan, S. and Solete, P. (2015). Cone-beam Computed Tomography Evaluation of Root Canal Preparation using Various Rotary Instruments: An in vitro Study. The Journal of Contemporary Dental Practice, pp. 869-872. doi: 10.5005/jp-journals-10024-1773.

Ramesh, A. et al. (2018). Comparative estimation of sulfiredoxin levels between chronic periodontitis and healthy patients - A case-control study. Journal of periodontology, 89(10), pp. 1241-1248.

Rashid, H., Hanif, A. and Nasim, M. (2015). Tooth surface loss revisited: Classification, etiology, and management. Journal of Restorative Dentistry, p. 37. doi: 10.4103/23214619.156643.

Ravinthar, K. and Jayalakshmi (2018). Recent Advancements in Laminates and Veneers in Dentistry. Research Journal of Pharmacy and Technology, p. 785. doi: 10.5958/0974-360x.2018.00148.8.

Samuel, M. S. et al. (2019). Efficient removal of Chromium (VI) from aqueous solution using chitosan grafted graphene oxide (CS-GO) nanocomposite. International journal of biological macromolecules, 121, pp. 285-292. Samuel, S. R., Acharya, S. and Rao, J. C. (2020). School Interventions-based Prevention of Early-Childhood Caries among 3-5-year-old children from very low socioeconomic status: Two-year randomized trial. Journal of public health dentistry, 80(1), pp. 51-60.

Sathish, T. and Karthick, S. (2020). Wear behaviour analysis on aluminium alloy 7050 with reinforced $\mathrm{SiC}$ through taguchi approach. Journal of Japan Research Institute for Advanced Copper-Base Materials and Technologies, 9(3), pp. 3481-3487.

Sharma, P. et al. (2019). Emerging trends in the novel drug delivery approaches for the treatment of lung cancer. Chemico-biological interactions, 309, p. 108720.

Shenoy, A. and Shenoy, N. (2010). Dental ceramics: An update. Journal of conservative dentistry: JCD, 13(4), pp. 195-203.

Siddique, R. et al. (2019). Qualitative and quantitative analysis of precipitate formation following interaction of chlorhexidine with sodium hypochlorite, neem, and tulsi. Journal of conservative dentistry: JCD, 22(1), pp. $40-47$.

Soares, C. J. et al. (2017). Polymerization shrinkage stress of composite resins and resin cements - What do we need to know? Brazilian Oral Research. doi: 10.1590/18073107bor-2017.vol31.0062.

Sridharan, G. et al. (2019). Evaluation of salivary metabolomics in oral leukoplakia and oral squamous cell carcinoma. Journal of oral pathology \& medicine: official publication of the International Association of Oral Pathologists and the American Academy of Oral Pathology, 48(4), pp. 299-306.

Teja, K. V., Ramesh, S. and Priya, V. (2018). Regulation of matrix metalloproteinase-3 gene expression in inflammation: A molecular study. Journal of conservative dentistry: JCD, 21(6), pp. 592-596.

Varghese, S. S., Ramesh, A. and Veeraiyan, D. N. (2019). Blended Module-Based Teaching in Biostatistics and Research Methodology: A Retrospective Study with Postgraduate Dental Students. Journal of dental education, 83(4), pp. 445-450. 
Venu, H., Raju, V. D. and Subramani, L. (2019). Combined effect of influence of nano additives, combustion chamber geometry and injection timing in a DI diesel engine fuelled with ternary (diesel-biodiesel-ethanol) blends. Energy, 174, pp. 386-406.

Venu, H., Subramani, L. and Raju, V. D. (2019). Emission reduction in a DI diesel engine using exhaust gas recirculation (EGR) of palm biodiesel blended with $\mathrm{TiO} 2$ nano additives. Renewable Energy, 140, pp. 245-263.

Vignesh, R. et al. (2019). Management of Complicated Crown-Root Fracture by Extra-Oral Fragment Reattachment and Intentional Reimplantation with 2 Years Review. Contemporary clinical dentistry, 10(2), pp. 397-401.

Vijayakumar Jain, S. et al. (2019). Evaluation of ThreeDimensional Changes in Pharyngeal Airway Following
Isolated Lefort One Osteotomy for the Correction of Vertical Maxillary Excess: A Prospective Study. Journal of maxillofacial and oral surgery, 18(1), pp. 139-146.

Vijayashree P. J. (2019). In silico validation of the non-antibiotic drugs acetaminophen and ibuprofen as antibacterial agents against red complex pathogens. Journal of periodontology, 90(12), pp. 1441-1448.

Website (no date). Available at: https:// www.scopus. com/inward/record.url? eid=2s2.0- $85071307044 \&$ partnerID $=40 \&$ md 5 $=$ ef0e25bc67730732dd0f8fecacb7b 64d (Accessed: 12 June 2020).

Zhang, Y. and Kelly, J. R. (2017). Dental Ceramics for Restoration and Metal Veneering. Dental clinics of North America, 61(4), pp. 797-819. 